\title{
Analysis about current status of English phonetics in China
}

\author{
Chunyi Zhou
}

Ankang University, Ankang, 725000, China

\author{
Keywords: English; Phonetics; Current status
}

\begin{abstract}
This thesis collects a number of domestic, foreign and related CNKI documents and finds many theses related to English phonetics. It classifies English phonetics according to comparative research on connotation of phonetics, basic knowledge of English phonetics and English phonetic teaching as well as experimental research on English phonetics. Besides, this article also analyzes related domestic and foreign research. Based on this, it summarizes current status of Chinese research on English phonetics and points out research achievements of English phonetics and shortages existing in the process of research. At the same time, it proposes some suggestions for future research on English phonetics, hoping to provide some theoretical reference and examples for related study.
\end{abstract}

\section{Introduction}

Throughout research on English phonetics in China, it has some advantages in the aspect of quantity, which also proves that practical application of phonetics has drawn attention. Meanwhile, research on supersegmental phonemes begins to be listed in schedule. However, according to careful observation about these articles, it is easy for us to find that these kinds of research stay in traditional discussion methods and fail to provide effective and objective basis for municipal administration. It is necessary to develop research on use of modern instruments and supersegmental phonemes further. Under such a background, this article analyzes and studies research status about English phonetics in China further and mainly carries out summarization and draws conclusions about current status of English phonetics in China in the aspects of comparative research on connotation of phonetics, basic knowledge of English phonetics and English phonetic teaching as well as experimental research on English phonetics. In fact, research on English phonetics in China is not successful all the time. This article points out problems existing in research process and puts forward some suggestions for future research on English phonetics simultaneously. It will analyze and discuss current status of English phonetics in China in the following passages.

\section{Analysis about connotation of phonetics}

From the second half of the 19th century, modern phonetics was divided into two branches inside the subject, i.e., phonology and experimental phonetics. From the 1920s, the two different subjects became independent subjects and developed along their own roads. Experimental phonetics (phonetics for short) is a science that uses computer, acoustics and advanced equipment etc to disclose generation process of phonetics and acoustic features. Tracks about development of phonetics can be found at any place where phonetics is needed for communication. Up to now, phonetics has become a science that approaches practical application most in phonetics science.

Phonetics is an effective tool in English study. There is numerous related research on English phonetics in China at present. Such analyses and research represent important research achievements in this field to some extent. In accordance with profound analysis of these articles, we may divide these articles into four kinds. Firstly, research on basic theoretical knowledge about English phonetics is involved, which is classified into two different aspects, i.e., research on vowel, consonant and syllable and study on supersegmental phonemes. Besides, it also contains research on stress, intonation and rhythm. Secondly, research on English phonetic teaching is contained. The third kind refers to research on phonetic comparison and the fourth one involves research on 
English phonetics by modern science and technology, which also contains study on phonetic teaching and phonetics. We will analyze the four different aspects specifically in the following, hoping to help us learn specific situations about research on English phonetics clearly in China at present.

\section{Status analysis about research on English phonetics in China.}

(I) Research on basic knowledge about English phonetics

1. Related study on vowel, consonant and syllable

English is a language combining pronunciation and meaning. English phonetics not only affects our pronunciation but also has influence on English grammar to some extent. Therefore, an important basis on which we can learn English well is to master phonetics effectively. In addition, acquisition of other languages except for English is based on phonetics. Hence, it is obvious that English phonetics is an important precondition on which we may learn English well to some extent. There have been a few research theses on pure theory of phonetics in China in recent years. For instance, On Rules about short Sound in English (Huang Xiaoping, 2000) and Learn Some English Phonetics: Syllable (You Wuli, 2003) mainly introduce importance of English phonetics and theoretical knowledge about phonetics in the aspect of English phonetics classification. Most theses focus on combination between phonetic knowledge and general theory teaching. For example, Shandong Foreign Language Teaching and Phonetic Knowledge in English Teaching (Xia Rong, 2004) mainly emphasize that segmental phoneme training may be used as a basis of English teaching and put forward importance of phonetic teaching reform. Besides, the article Research no Correlation between English Phonetic Knowledge and Listening Competence (Sui Min, 2000) points out there is correlation between listening ability and phonological competence to some extent.

2. Research on supersegmental phonemes

In the process of language use, both vowels and consonants are emphasized. At the same time, single syllables and acquaintance and mastery about supersegmental phonemes are emphasized as well. Supersegmental phonemes mentioned here mainly contain intonation, stress and rhythm. Such content has significant influence on accuracy and flexibility of our pronunciation and our actual oral English level can be reflected by these aspects.

The thesis Comparative Study on Segmental Phonemes between English and Chinese (Xiang Hong, 2001) mainly elaborates phonetic segmental phonemes of English and Chinese have close relationship, compares such a close correlation deeply, carries out practical application of this comparative and analytical method and studies relations among English phonetics, pronunciation of standard spoken Chinese and local language in Hunan via this comparative and analytical method. The article Comparative Research on functions of supersegmental phonemes in English and Chinese (Chen Ying, 2002) deems that supersegmental phonemes in English and Chinese are the most important part in English study and compares and analyzes the three stress, intonation and rhythm simultaneously. In the process of functional comparison, stress and rhythm are the most important in caparison about relationship among segments, other grammars and phonetic components. At the same time, functions of the three in this relationship are compared and analyzed. Additionally, it points out research is also appropriate in foreign language teaching, translation and international communication. Based on this, it studies supersegmental phonemes in English and Chinese further and puts forward several related suggestions.

(II) Research on phonetic teaching

English language teaching at the early stage centered on grammars. Exam-oriented education takes the lead in English teaching of China. Being affected by exam-oriented education, English teaching centers on textbooks and grammars and treats vocabulary recitation as an important basis of English study. Such a teaching method has had significant influence on Chinese students and affected their ability to apply English language seriously all the time. However, research on English phonetics has developed constantly in recent years. English phonetic teaching in China at present also begins to change from traditional phonetic teaching into diversified teaching of speech training. 
Currently, related research on theses is mainly divided into three different kinds, i.e., research on phonetic teaching of non-English majors, research on phonetic teaching for children and primary and secondary school students and research on phonetic teaching for English majors. For instance, Acceleration of Speech Training on Kids' Consciousness of English and Knowledge about Letters (Zheng Xiaobei, 2009) makes full use of phonetic teaching experiment and finds that children are significantly affected by phonetics in the aspects of syllable, rhyme, consciousness of phonemes and recognition about letters according to experiments. Children can get faster improvement in consciousness of English phonetics by specific speech training at an early stage. Research on English Phonetics of Junior Students at Kindergartens under Context of Cartoons (Meng Tinghan, 2008) mainly utilizes English cartoons, places research emphasis on results of tests on phonetic simulation and investigates effect of kids' phonetic study under different learning materials and teaching methods. These articles have a similar feature that they explore and analyze consciousness of children in the aspect of language acquisition from a careful perspective. Phonetic teaching in professional English and college English starts from mispronunciation found in the process of practical teaching and Chinese-style pronunciation, analyzes and discusses causes for such mistakes and problems and current status of phonetic teaching in China and proposes related strategies for improvement in students' pronunciation ability based on this, for example, the article English Phonetics and College English Teaching (Zhang Qiong, 2004).

(III) Comparative research on English and Chinese phonetics

From the 1920s, western linguists began to use comparative analysis to carry out comparative research on several different language functions and structures. Chiense scholars, for instance, Zhao Yuanren, began to study differences and similarities between English and Chinese phonetics in the 1930s further.

Currently, most research compares English and Chinese. Such comparison is divided into comparison between syllables and supersegmental phonemes and comparison about phonetic system. There is little research on rhythm, intonation and stress in supersegmental phonemes. Research in these articles mainly aims at providing convenience for teaching, primarily starts from Chinese, finds out positive and negative correlation and analyzes causes for appearance of Chinglish. A small part of research focuses on comparison between English and dialects, places research emphasis on negative transfer effect of dialects on English and discusses practical problems existing in English teaching and related countermeasures.

(IV) Experimental research on English phonetics

Experiments are an effective auxiliary method by which we can study English phonetics. From the $20^{\text {th }}$ century, this experimental method gradually changed into an independent subject. Especially in the 1970 s, electronic computers were introduced to phonetic research and use of such computers enabled people to process a large number of data at different time. At this moment, the experimental method was widely developed, which also promoted joint development of phonetic acoustics, physiology and perception. Overall, the number of articles in related research is small in related research. Primary research concentrates on combination between it and experimental phonetics and accounts for a major part, which makes full use of experimental phonetics, uses experimental instruments to obtain accurate and specific data and materials and then analyzes features of English phonetics future. A small number of other articles mainly study teaching experiments, analyzes phonetic mistakes that students encounter in the learning process specifically and mainly uses the way that combines with Chinese phonetic experiments to carry out further comparative research.

\section{Conclusion}

In conclusion, by settling the foregoing articles, related research on English phonetics grows increasingly, which also proves that phonetics draw more and more attention in the process of practical application. Especially, according to research in this article, it is found that China has begun to pay attention to research on supersegmental phoneme nowadays. However, after analyzing these articles comprehensively, we may find that most of these kinds of research only stay in 
traditional discussion methods and it is necessary for us to develop the research that can provide effective basis for study development of English phonetics and develop experimental analysis by using modern instruments to larger extent. With respect to research on phonetics, study on supersegmental phonemes need be deepened further. Especially, research on stress, intonation and rhythm need be carried on further. Meanwhile, it is essential to combine modern science and technology with English phonetics effectively, makes full use of modern multimedia teaching technology, make it become an effective teaching method of English phonetic teaching and provide brand-new research thoughts for English phonetic teaching.

\section{Acknowledgments}

This thesis is a special project of Shaanxi Education Department's scientific research plan. Task name is Research on professional development of rural primary school teachers in Southern Shaanxi and project No. is $14 \mathrm{JK} 1007$.

\section{References}

[1] Yan Ning. Phonetics and phonology: Academic field and development prospect [J]. Journal of Yunnan University of Finance and Economics(Social Science Edition), 2008(3).

[2] Lin Shaorong. Analysis of current status of research on English phonetics and teaching in China and suggestions [J]. Journal of Fujian Agriculture and Forestry University (Philosophy and Social Sciences Edition), 2012(2).

[3] Pei Zhengwei. Investigation on English phonetic ability of non-English majors and research on affecting factors [J]. Journal of Dongnan University (Philosophy and Social Sciences Edition), 2012(6).

[4] Fang Rui. Good pronunciation is quite important - Thinking on effectiveness of English phonetic teaching [J]. Journal of Hunan University of Science and Engineering, 2009(3).

[5] Cai Longquan, Song Xuedong. Communication, variation and standard: on orientation of English pronunciation in China [J]. Journal of Shanghai Normal University (Philosophy and Social Sciences Edition), 2009(6).

[6] Zhang Qing, Lu Haiyan. Research on training about English phonological awareness on learning effect of rural children's English vocabulary study - Take an ordinary primary school in Luoyang, Henan for example [J]. Journal of Luohe Vocational Technology College, 2013(1).

[7] Gong Minli, He Guangkeng. Investigation on English phonetic study of senior high school students [J]. English Teachers, 2013(5).

[8] Yang Jinfeng. Research and reference about application of Canadian TPR to College phonetic teaching [J]. Contemporary Educational Science, 2013(15).

[9] Chen Hua, Wen Qiufang, Li Aijun. A new platform of research on phonetics: speech database for English learners in China [J]. Foreign Language Research, 2010(1).

[10] Ma Yinglian. Inheritance of A.C. Gimson phonology — reading Research on English Phonetics written by Yin Zhilei [J]. Journal of Tianshui Normal University, 2009(6).

[11] Wang Yi, Feng Jingchao. Investigation and analysis about English phonetic teaching and use of English international phonetic system at colleges [J]. Journal of Shanxi Normal University (Social Science Edition), 2010(3).

[12] Qiu Qingwei. Analysis of learning situation and teaching strategies for English phonetics at colleges [J]. Journal of Chongqing College Electronic Engineering, 2012(4). 